\title{
Reflective Practice in a Cross-Cultural University Setting: A Theoretical Model
}

\author{
Maher Khelifa \\ Zayed University, UAE
}

\begin{abstract}
The trend in education is shifting toward a greater concern with learning. In this new model, teachers are required to constantly reflect on their pedagogy to sustain student interest and engagement. This reflective inquiry is particularly important when the teacher and students are of different language and culture as in the case of Zayed University, UAE. Such cross-cultural context often complicates the learning environment resulting in confusion, stress, and frustration for faculty and students. It also results in a reduced teaching effectiveness and a need to regularly adapt tried methods of teaching in Western universities with the educational background of students. This process requires deep reflection and cultural adjustment. This study therefore investigated the challenges, critical inquiry, and adjustments of Western faculty in the delivery of an American curriculum taught in English to Emirati female students. The study also sought to derive a theoretical model explaining faculty reflective processes in cross-cultural classrooms.
\end{abstract}

\section{Introduction}

A great challenge in teaching is to create and maintain an interesting and intellectually stimulating classroom environment in which students eagerly learn and grow. This challenge requires teachers to frequently examine their teaching practices and to reflect critically in order to introduce changes to their teaching when needed. The scope of change is wide and varies from changes in teaching philosophies, to changes in classroom materials and teaching strategies. Change is usually achieved through a continuous reflection and action and an open dialogue with students and colleagues.

As much as the process of reflective practice and teacher change is taxing, it is rewarding (Fitch \& Kirby, 2000; Shatz, 2000; Sommer \& Sommer, 1991). It leads to greater mastery, efficacy, and satisfaction in the profession of teaching (Fullan \& Hargreaves, 2002; Paulus Nicol, 2000). Teachers who change generally grow and lead their students to growth as well. They are reflective and critical of themselves and continuously try to do what is needed for the best interest of their students.

This critical inquiry process is particularly important when the teacher and student belong to different cultures (Jennings \& Smith, 2002) and the language of instruction is foreign to the student (Khelifa 2007; Khelifa \& Sonleitner, 2006). In these teaching and learning contexts, sustaining students' motivation to learn becomes a daily challenge for teachers. The cultural differences of the student-teacher dyad tend to complicate learning, particularly when the teaching methods and assumptions about learning are not filtered through the local culture of the students.

This study therefore investigated the challenges faced by Western faculty in the delivery of an Americanmodeled curriculum taught in English to Emirati students. It also examined the critical inquiry and the teaching adjustments faculty make in the pursuit of teaching effectiveness. Finally the study sought to 
derive a theoretical model that explains faculty reflective processes in cross-cultural higher education classrooms.

\section{The Cross-Cultural Nature of the Educational Setting}

For readers to understand this paper, it is necessary to shed light on the unique characteristics of the study university, its faculty and its students. This includes a description of the university goals, a general overview on the nature of the curriculum, the medium of instruction, faculty make up, student characteristics, and their pre-university educational background. This synopsis also includes a description of the faculty-student dyad and how this often results in an incompatible mix creating conflicts, confusion and a need for faculty with western experience to regularly adapt proven methods of teaching.

\section{The Institution}

Zayed University (ZU) is a young higher education institution founded in 1998 in the United Arab Emirates. Until recently ZU had two main campuses: one in Dubai and one in Abu Dhabi (referred to as Abu Dhabi South Campus). Both campuses are managed by a single administration and offer similar programs. For 10 years, ZU was strictly dedicated to the education of Emirati female students. Lately the university has started accepting applications from female students of all nationalities in Dubai and Abu Dhabi main campuses. Also, a new campus in Abu Dhabi - referred to as Abu Dhabi North Campus - has opened its doors to male Army Cadets. Future expansion plans also exist for Fall 2009 and these include accepting other male undergraduates for the new North Campus in Abu Dhabi and the ZU Knowledge Village Campus in Dubai.

$\mathrm{ZU}$ is distinctive for being the only university in the region receiving US accreditation. Other features that distinguish the University include the exclusive recruitment of Western or Western-educated faculty. ZU is also distinctive for its student-centered mission, its outcome-based learning environment, its emphasis on technology in teaching and learning, and its intent to provide an American-like education to Arab students. Further, the instruction is delivered strictly in English with the exception of a few courses in Arabic. The language of instruction is therefore English within the context of Arab culture and society. For most students, especially those coming from public high schools (free government high schools for Emiratis, fee-based schools for non-Emirati Arab nationals), English is more a foreign language than a second language. The university's entrance requirement for English language proficiency for public high school graduates is a minimum score of 150 on the Common Educational Proficiency Assessment test (CEPA English). Students admitted to the university are also required to take an English placement test which determines whether they qualify for a direct entry to the baccalaureate program. Depending on the placement test results, students may be required to spend between ten weeks and two years learning English in the pre-baccalaureate Academic Bridge Program (ABP). The ABP consists of eight levels, each lasting ten weeks. On average, students coming to ZU from public high schools spend about two semesters working on their English language skills in the ABP. To exit the Academic Bridge Program, a student must achieve an IELTS score of 5.0 average (or 5.5 average if one of the scores is as low as 4.5). Comparable English language admission requirements are also in place for private school graduates and for transfer students from other UAE higher education institutions.

\section{The Students}

In line with local cultural rules of gender segregation, the university caters exclusively for national female students. Nearly all students wear the abaya (black cloak), and the shayla (headscarf), to cover 
themselves when in the presence of males. A small number of students wear the niqab (face veil). These students usually remove the veil when in the company of other females.

According to official ZU statistics, most students received their pre-college education in the United Arab Emirates and come from public high schools where English is only taught as a modern foreign language. A small number of students attended private schools where English is the main language of instruction (Russell et al., 2006). In line with prevailing Islamic values, public school students are in general socialized to regard the teacher as an authority figure; they are also trained to be passive learners, and to memorize facts (Sonleitner \& Khelifa, 2005) similar to Qur'anic school teaching styles. This kind of pre-college teaching/learning environment limits student critical thinking, and analytical and logical reasoning development. It also instills a concern and fear in students about making mistakes (Khelifa \& Sonleitner, 2006). Student educational background, combined with sex segregation (Russell et al., 2006), translates into students being passive learners in many contexts, and lacking information on global issues and events (Sonleitner \& Khelifa, 2005). Many students are from the first generation in their family to enter higher education.

\section{Faculty}

Teachers at ZU are mostly Westerners or have received a Western education. Countries of education include the USA, Australia, Canada, the UK, and New Zealand. Faculty educated in Arab countries such as Egypt are hired as part of the Arabic and Islamic Studies program. Western or Western-educated faculty frequently have Western world views and come to teach with a Western set of expectations and assumptions about teaching effectiveness, students' behaviors, attitudes, and performance.

\section{Faculty-Student Interface}

The dissimilarities between the students and their instructors in terms of language and cultural backgrounds create a cross-cultural teaching context with a unique host of teaching and learning challenges. These factors emerge as barriers to instructional effectiveness and students' learning and bring about significant amounts of stress and frustration in faculty and students alike. The interface between the two cultures appears to provoke confusion for new and continuing faculty alike. This confusion usually evolves into an ardent desire to adjust tried methods of teaching in Western universities with the educational backgrounds and particular attitude toward learning of Emirati national female students. This process very often requires a great deal of reflection and cultural and classroom adjustment, adaptation, and change.

\section{Method}

The purpose of this study was to investigate the pedagogical challenges for Western faculty brought about by the delivery of an American-modeled education to Emirati students in the Arabian Gulf. It also examined the critical inquiry and the didactical adjustments faculty make in the pursuit of teaching effectiveness in order to derive a theoretical framework that explains faculty reflective processes in cross-cultural higher education classroom contexts.

\section{Participants}

The study was conducted with Western faculty who have worked at ZU for at least one year at the time of questionnaire administration. The total number of continuing faculty (faculty having taught for at least one year at ZU) was 292. Participants for the study were selected through a simple random sampling plan using the computerized function of SPSS for Windows, version 14.0. A random sample of 40\% was generated corresponding to 120 faculty. The selected 120 faculty were approached for 
participation via campus mail. A total of 61 faculty (51\% response rate) from Dubai and Abu Dhabi campuses volunteered for the study and completed the survey.

\section{Instrument}

The study used a descriptive cross-sectional survey design. The analysis was based on data collected using a questionnaire especially developed for the study (see Appendix A). In addition to demographic information items, the questionnaire included 11 main questions that explore the type of classroom challenges continuing faculty regularly face, the reflective and critical processes faculty engage in as they seek teaching effectiveness, the mechanisms they put in place to deal with classroom inadequacies, the areas of change they make to their teaching, and the types of support they use in their reflective process.

\section{Procedure}

Participants received via campus mail a brown envelope containing a copy of the questionnaire, a cover letter, and a consent form. Participants were asked to return the filled out questionnaire and the signed consent form to the investigator using campus mail one week from receipt. The questionnaire was anonymous and participants were assured of confidentiality of information and of their right to withdraw from the study at any time without penalty.

\section{Data Analysis}

The analysis was based on data collected using the questionnaire. Quantitative data were analyzed at the descriptive and inferential levels. Open-ended responses were analyzed qualitatively using SPSS Text Analysis for Surveys version 1.0. This software allows the import of qualitative survey data from SPSS for Windows. Key concepts are then extracted automatically using the extractor engine which collects the most salient terms and patterns expressed in the survey responses for each open-ended question under analysis. Categories or codes are then created and refined for the data using manual and/or automatic analysis through the use of classification techniques such as term/text inclusion and semantic networks. Category results are later used for qualitative as well as quantitative analysis (SPSS Text Analysis for Surveys 1.0 User's Guide, 2004).

\section{Results and Discussion}

\section{Demographics}

Participants were 61 Western faculty with a minimum of 1 year teaching experience at ZU. In general, faculty have an average of 2.42 years of experience teaching at $\mathrm{ZU}(\underline{\mathrm{SD}}=1.29) .34$ faculty $(55.7 \%)$ were males and 27 (44.3\%) were females. The majority of participants were from the United States (54.1\%); many were from Canada (19.7\%) and the United Kingdom (14.8\%). A much smaller number of faculty were representative of Australia (6.6\%) and New Zealand (4.9\%). Most participants have earned a doctoral degree (63.9\%), one third (32.8\%) have earned a masters degree, and a few participants (3.3\%) were still working on their doctorate (ABDs) when data was collected.

As far as participants' academic rank is concerned, $32.8 \%$ were Instructors, $29.5 \%$ were Assistant Professors, $21.3 \%$ were Associate Professors, and 16.4\% were full Professors. On average, before joining $\mathrm{ZU}$, participants had taught in a Western institution for 9.9 years $(\underline{\mathrm{SD}}=8.44)$ at the undergraduate level, and for 4.3 years $(\underline{\mathrm{SD}}=7.07)$ at the graduate level. A large number of participants $(45.9 \%)$ have taught for an average of 5.6 years $(\underline{S D}=5.52)$ in a university where English is not the first language. None of the participants has taught exclusively at Gulf higher education institutions. 


\section{Western Faculty's Cross-Cultural Classroom Challenges}

Most professors (90.2\%) in the sample acknowledged that they have indeed encountered cross-cultural student-related classroom challenges when teaching at ZU. The most common issues faculty faced centered around student cultural classroom norms, atypical classroom behavior, poor level of classroom preparedness, lack of initiative and motivation for learning. Other significant challenges faculty faced related more to students' different expectations and assumptions about college education, workload, academic responsibilities; students' low academic maturity levels; and poor preparation for university by high schools.

In general, faculty were convinced that students were not properly socialized into university student roles. Many professors thought that new students would need at least half a semester to understand how a university works. According to most teachers, student classroom expectations and assumptions were very far from those of their professors. Faculty thought that students have unclear expectations of their university responsibilities with some going as far as saying that students have not been taught how to be taught. However, the intensity of faculty feelings may be connected with their expectations generated from Western educational models. Because the medium of instruction is English in an Arabic speaking culture, many faculty may get frustrated by the differences in their expectation for language and communication, compared to the English language ability they were experiencing in the West. Faculty in Western universities expect students to be prepared when they come to class. However, many professors in the sample were really frustrated that students do not prepare for class and do not exhibit the classroom behaviors they normally expect from students.

Some of the anomalous and problematic student classroom behavior that faculty frequently listed in their responses centered around the lack of self-discipline. This includes student tardiness, strolling in and out of the classroom during lessons, difficulty to maintain students on task especially as they engage in side discussions, talking and giggling in class, online chatting, reading and sending email in class, and using mobile phones during lessons. Other issues centered around student classroom responsibilities, for example not bringing books, pencils, and notebooks to class. Faculty also complained about students not taking notes, not completing assignments and homework, and not adhering to deadlines. Other frequently cited classroom challenges included the lack of student valorization of knowledge, lack of initiative and motivation to learn, shyness, lack of participation in class discussions, and lack of free expression of opinions especially when commenting on other students' work. Professors' complaints also included student high grade expectation for very limited levels of achievement, and lack of respect for the teacher and fellow students.

Other significant cross-cultural classroom issues faculty encountered related rather to students' low academic maturity and preparation for university by high schools. Faculty stressed that students have strong deficiencies in English language ability, literacy, global awareness, study skills, research and library skills, and ability to use teacher feedback to improve their work. Other issues faculty listed include low student critical thinking skills and ability for abstraction, limited focus and knowledge transference skills, and a low capacity for independent work and learning.

\section{Faculty Reflective Practice and Cross-Cultural Classroom Adjustments}

Reflective practice may carry different meanings (Richardson, 1990) but one common element of reflection is the notion of problem (Loughran, 2002). John Dewey (1933), whose ideas are considered the basis of the current thought about reflection (Canning, 1991), noted that "demand for a solution of a perplexity is the steadying and guiding factor in the entire process of reflection" (p. 14). Schön (1983, 1987) who introduced the concept of reflective practice into current discourse, views reflection as occurring in-action and on-action. Greenwood (1993) argues, however, that Schön's theory has 
neglected the important element of reflection before action. More on this can be found in the works of Van Manen (1997), Schön (1983, 1987), Kolb (1984), Tom (1985), Smyth (1988), Richardson (1990), Boud and Walker (1990), and Walker and Boud (1992). In general, reflection is expected to foster the ability of teachers to think flexibly and objectively about classroom problems (Risko et al., 2002), to learn from their own teaching actions (Jones \& Vesiland, 1996), and to spontaneously find solutions for problems that arise out of specific classroom situations (Cervero, 1992; Schön, 1987).

For most faculty in the sample, the current educational environment departs significantly, both academically and culturally, from Western universities they were affiliated with previously. Therefore, they felt frequently compelled to adjust many elements of their teaching to maximize student learning. Participants had to learn what they termed "Gulf classroom management" by adjusting the way they prepare for class, teach, or assess student work, particularly in terms of building in flexibility and incorporating more regular reflective assessment of their teaching effectiveness.

The majority of faculty in the sample $(90.32 \%)$ indicated devising strategies to deal with the teaching challenges they were frequently facing in the classroom. A sizeable majority (87.1\%) indicated that their strategies included changes to their teaching. In general, the teaching areas faculty needed to change include their teaching method $(85 \%)$, teaching pace $(85 \%)$, in-class explanation $(81 \%)$, course content (75\%), motivational strategies (66\%), language use (59\%), course preparation (55\%), assessment rigor $(42 \%)$, grading practices $(40 \%)$, and expectations of student performance $(38 \%)$.

A lot of faculty (16.7\%) pointed that they make changes to their teaching almost every class. A similar number said they introduce changes to their teaching as frequently as every week $(16.7 \%)$ or every month (18.8\%). The remainder indicated introducing teaching changes at normal rates such as after every semester $(25 \%)$ or every year $(22.8 \%)$. In general, faculty stressed that changes were introduced "as needed" regardless of how often. One faculty pointed out: "I introduce changes whenever needed. If after reflection I find that there is room for improvement, then I would make the necessary changes." Other teachers made the point that introducing changes to prepared lessons is an ongoing process in their respective classrooms: "Teaching effectively and reaching students is a dynamic process in which you conduct current interaction with students based on their needs and development. The nature of teaching requires that you change the approach if the students aren't 'getting it'." Following is a qualitative account of faculty reflection and the many adjustments they made to enhance their classroom performance and student learning.

Due to student English language limitations, most teachers needed to slow down their pace considerably, covering far less material than expected in comparable Western classrooms. One faculty acknowledged: "I lowered my expectations considerably. Language is crucial and without adequate ability students cannot keep the pace I would have expected or accomplish what I expected of them, with a very few exceptions." Another teacher commented: "I can only cover a fraction of the material I would in courses back in the States. Not only can I not use senior level material for senior level classes, I cannot use freshman level material unless I re-write it." In general, many teachers had to filter content to include what they thought could best be understood by students. Others were obliged to drop class material not considered critical to allow for a slow and in-depth coverage of what was thought essential to the course. This included cutting down on the amount of required reading because of the comparatively high level of English in many of the western college textbooks. Some considered the matter more philosophically and felt no pressure in dropping the pace so long they are responsive to student learning needs. Still others felt a stronger need to adjust the pace and adopt a more flexible attitude towards teaching to reach more students and effect more learning rather than blindly following a rigid syllabus. As one faculty noted: "I do not stay with a set pace, I go by how the work is going in the 
class. This may mean canceling a preplanned activity. I feel this works better than pushing through an agenda no matter what".

Presenting lessons takes more time not only because of having to repeat material more often, but also because teachers have to think of how to present abstract concepts and theories in a much simpler form. One teacher said: "I find I have to speak more slowly, more distinctly and repeat information more frequently than I ever did before coming to ZU." Many faculty had decided that English was an obstacle and that images in the form of videos and graphics would say a lot more than written words. Even though faculty presented course material at a slower pace, used visual images to increase communication, there would still be difficulties with content. This may come from student background in rote learning. Unlike education in the West, understanding and applying concepts was not the focus of their pre-college education, and being able to regurgitate memorized information was encouraged.

Because of student English language deficiencies, most teachers in the sample had to alter their classroom expectations to what they thought was realistic to anticipate from students. Many indicated moving to a reduced expectation of standard of English expression and conceptual grasp. Faculty took nothing for granted and adjusted their teaching methods. These alterations included trying a variety of techniques such as an increased use of visuals and interactive teaching material. Teachers simplified their language use to include easier terminology and concepts, a reduced use of jargon and idioms, and made sure to introduce regular checks to ensure student understanding of content. Teachers also used more frequent pauses, more frequent repetitions, and lengthier and simpler in-class explanations incorporating examples that students can easily identify with.

Faculty struggled to gain student interest and motivation, and expressed frustration with perceived student apathy. They also were concerned with the amount of effort and creativity required to motivate and see in students a commitment to learning. Nonchalance was what faculty concluded from student tardiness in class attendance and turning in homework, and apparent non-readiness for class-time. When motivation is not there, when students seem apathetic, it has the effect of prompting faculty to try techniques and strategies to stimulate students into active learning (Dyer, 1998; Khelifa, 2007; Long, 1999; Shatz, 2000; Sommer \& Sommer, 1991). Faculty experimented with different motivational strategies to sustain student focus and engagement including the use of student presentations, class discussions, group work, and creative projects. In general, faculty adjusted their teaching to include more hands-on projects and activity-centered orientation. They changed their teaching approach to interactive and collaborative methods instead of using a lecture format. As reported by many faculty, the abundant use of praise and a focus on what the students can do well seemed to pay off.

Preparing class for most faculty involved spending much more time on activities such as searching for illustrations to portray concepts visually. Faculty participants reported that when they prepared materials for class they used resources from publishers more than they had before. Some faculty commented that having multiple sections of the same course allowed for piloting the prepared lesson and having an opportunity to modify the lesson for subsequent sections. Other faculty were frustrated in planning class lessons not only because of students' grasp, but also because of logistical problems. Faculty also struggled with new preparations, or preparing for classes they had taught before but needed to re-do for the academic and cultural context.

Assessment rigor and grading practices have changed as well. Students in ZU appear to get overwhelmed when normal size tests or projects are proposed in English. Many faculty found that implementing frequent small assessments produced better outcomes and provided ongoing feedback on student progress. Many others introduced daily assessments on much smaller parts of projects done in class to foster student accountability and progress. Some faculty resorted to reducing assessments to 
a mid-term and a final to pay more attention to learning rather than testing. Faculty also struggled sometimes with striking a balance between the low quality of submitted written work and the grades given to students. A sizeable number of faculty devised assessments that give students a variety of ways to highlight their progress.

Teachers at $\mathrm{ZU}$ have, in general, become more sensitive to the course content to be covered in an Arab and Muslim context, with some teachers indicating removing course material to respect the local culture. Participants also mentioned that they continue to feel nervous about potential unintentional violations of local cultural taboos when presenting class material. Some faculty expressed the difficulty they were having because the non-verbal behavior they experience in Western students was lacking in the students they were teaching in the study institution.

\section{A Theoretical Model}

In describing the process faculty undergo in developing teaching strategies to address the classroom challenges they face, common themes have emerged suggesting a lot of resemblance and commonality in how faculty reflect and propose change in culturally different classrooms. Below, is a suggested theoretical model (Figure 1) for faculty reflective process in cross-cultural classroom settings.

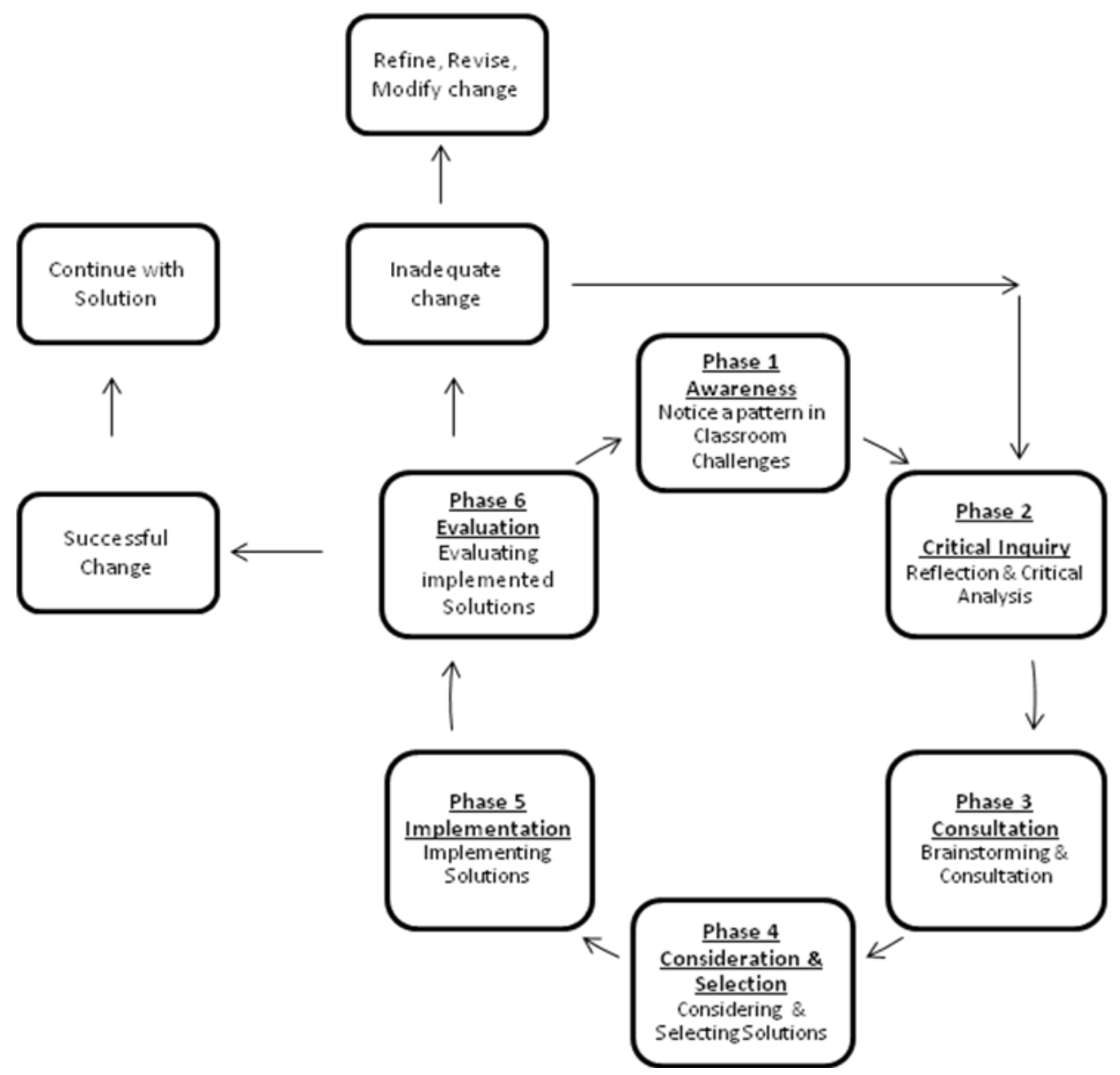

Figure 1: Theoretical model for faculty reflective processes in cross-cultural classroom settings. 


\section{Phase 1: Awareness}

The model above suggests that faculty critical inquiry and reflective process is triggered by a repeated experience of a cross-cultural classroom issue such as student apprehension to participate in class or student lack of motivation. Phase 1 is therefore an "awareness" or a "problem recognition" phase initiated when faculty notice a certain pattern in student behavior. At this time faculty begin to realize that they are facing a recurrent issue for which they need to find a timely solution. One faculty noted: "I experience a classroom challenge, I worry about it, I get annoyed about it. I experience it again and I know I have a problem." Another faculty made the point: "I felt terrible and felt the class was a disaster. I recognized the problem and realized that the whole semester would not work out if I do not make changes right away."

\section{Phase 2: Critical Inquiry}

This phase begins when faculty initiate their "critical inquiry" about what has happened and what went wrong in class. In this phase, faculty begin to think about why this is an issue. Faculty explore whether the situation relates to a classroom management issue or relates to the goodness of fit of the proposed content (curricular issues). Faculty conduct a self-examination of their teaching methods and a reflection on their work whenever they believe that the problem is curricular in nature. This reflection can be inaction (while they teach) or on-action (on what was proposed) (Schön, 1983). If the issue relates more to student behavior and classroom management, then faculty engage in a critical assessment of how pervasive and serious the problem is, as well as what kind of ramification will this have on subsequent lessons. Again, this reflection can be in-action (while they teach) or on-action (on their personal behavior in relation to observed student behavior).

\section{Phase 3: Consultation}

This phase is generally characterized by faculty shifting their focus to "brainstorming" and "problemsolving". In this phase, faculty consult with experienced colleagues about students' struggles with classroom material or the problematic student behavior trends they have experienced. This usually happens informally in settings where faculty of the same university congregate (teachers' lounge, cafeteria, hallway etc.). The consultation process also includes soliciting feedback from students and consulting informative literature (relevant scholarly journals and books) in view of finding solutions. One faculty had this to say about the consultation phase: "I discuss trends with students and colleagues looking for causes and consequences. Concurrently, I consult related literature considering alternatives, solutions, or ways to enhance my method." It is in this phase that faculty search for ideas and generate a host of solutions to the problem(s) encountered in class. These solutions may be derived from one or more of the three mentioned sources or reached creatively by the faculty him/herself.

\section{Phase 4: Consideration and Selection}

Phase 4 is a time for faculty to "consider and select" a solution from a list of alternate ones. The solutions considered are typically crafted to deal with the recognized issue(s). This is a decision-making time for faculty which can be done alone or in consultation with other faculty or students. One faculty pointed out: "I list possible solutions in rank order, I talk with student or colleagues and choose the 'best' solution first." Once a solution is selected, an action plan is usually put in place to implement the chosen strategy.

\section{Phase 5: Implementation}

This phase is simply a time for faculty to try out a select solution/strategy to control the problem. As solutions are implemented faculty actively observe the impact of the introduced solutions. They are 
somewhat in a comparative mode contrasting the previous strategy to current solution and informally collecting clues and information from student behavioral responses on how things are going (e.g., student in-class participation, in-class discussions, gestures, facial expressions, behavior etc.).

\section{Phase 6: Evaluation}

As faculty experiment with the introduced solution/strategy, they intuitively assess the effects of the implemented changes on controlling the classroom issue they grappled with initially. If successful, faculty typically retain and continue with the solution/strategy that has worked. If the solution doesn't work, faculty in general cycle back to Phase 2 or refine, revise/modify the solution/strategy as needed to reach the desired outcome.

\section{Conclusion}

The concept of critical reflective practice is often invoked as a distinctive element of good practice in education. Qualitative data from this study contain many examples of efforts faculty put forth, including introspection and consultation with the aim of bridging the cross-cultural gap and creating strategies to gain a connection with students. It is hoped that new and experienced teachers working in higher education institutions in the Gulf region and perhaps others who teach in similar cross-cultural contexts, find this discussion helpful and informative. It is especially hoped that this discussion guides faculty to consider other reasons for classroom deadlock than student lack of motivation, preparation, or proficiency in English. It is simplistic to think that student classroom struggles can be attributed entirely to students' poor academic preparedness and low English language ability. There may be other elements including some that are cross-cultural in nature and others that are purely pedagogical that are well within the instructor's control (Khelifa, 2009). For instance, Thielfoldt and Scheef (2005) highlighted the importance of understanding generational differences and how this understanding can be used in mentoring the new generations. When faculty also move from teaching exclusively at the graduate level to undergraduate teaching, different teaching approaches and strategies are required especially when teaching in a culturally different setting. Additionally, in the Gulf region in particular, the student and the teacher gender may constitute crucial elements that can either facilitate or complicate learning. It would be very interesting to examine in future studies whether classrooms of different or same-sex teachers would create a difference in terms of teaching and learning. It would also be interesting to investigate whether mixed or same-gender classrooms will affect learning in similar cultural contexts.

In all likelihood, Western faculty may need to dig deeper to identify and harness the sort of classroom processes discussed in this paper. Faculty need to adopt an internal locus of control in relation to classroom challenges by accepting responsibility for classroom disappointments regardless of their nature. With frequent and serious reflection about one's own teaching, faculty put themselves in a position to develop a variety of ways to deal with any inherent cultural mismatch or other learning issues. Faculty immersion in culturally dissimilar classrooms always promises to be different, confusing, frustrating, and challenging. But with effort, the experience may ultimately be unique, rich and fulfilling as faculty are pressed to give more consideration to their teaching, and to frequently rethink and retool their tried method of teaching.

As described above, the reflective process Western faculty went through time and again in a culturally dissimilar classroom appear to follow a common and organized pattern. It would be interesting to examine if the proposed theoretical model is descriptive of normal classrooms where faculty and students belong to the same culture. With the increased globalization of education, it would be worthwhile to ascertain if the model is also characteristic of other culturally different student-teacher dyads especially in the context of distance learning. As global learning continues to gain popularity, 
similar studies may prove invaluable as they have the potential to inform teachers on the nature of cultural and academic issues encountered in the classroom, the critical inquiry process faculty may need to go through, and the way resolutions are sought and implemented in such contexts.

\section{References}

Boud, D., \& Walker, D. (1990). Making the most of experience. Studies in Continuing Education, 12 (2), 61-80.

Canning, C. (1991). What teachers say about reflection. Education Leadership, March 18-21.

Cervero, R. M. (1992). Professional practice, learning, and continuing education: An integrated perspective. International Journal of Lifelong Education, 11 (2), 91-101.

Dewey, J. (1933). How we think. New York: Heath.

Dyer, B. (1998). Reflective teaching practice in cross-cultural contexts: Teaching women's studies in Japan. Women's Studies Quaterly, 3 (4), 152-166.

Fitch, B., \& Kirby, A. (2000). Students' assumptions and professors' presumptions. College Teaching, Vol. $48(2), 47-48$.

Fullan, M., \& Hargreaves, A. (2002).Teacher development and educational change. In M. Fullan, \& A. Hargreaves (Eds.), Teacher Development and Educational Change (pp. 1-9). Philadelphia, PA: Routledge Falmer.

Greenwood, J. (1993). Reflective practice: a critique of the work of Argyris and Schön, Journal of Advanced Nursing, 18, 1183-1187.

Jennings, L.B., \& Smith, C.P. (2002). Examining the role of critical inquiry for transformative practices: two joint case studies of multicultural teacher education. Teachers College Record, 104 (3), 456-81.

Jones, M. G., \& Vesiland, E. M. (1996). Putting practice into theory: Changes in the organization of prospective teachers' pedagogy knowledge. American Education Research Journal, 33 (1), 91-117.

Khelifa, M. (2007). Teaching Challenges in a Cross Cultural Classroom Context: American Education in the Arabian Gulf. Proceedings of the Second Annual Education and Development Conference. Bangkok, Thailand, March 9-11 2007.

Khelifa, M. (2009). On Joining Classroom Discussions: Arabic-Speaking Emirati Females in First Year English-Speaking University Classrooms. Unpublished Manuscript.

Khelifa, M., \& Sonleitner, N. (2006). Cross-cultural classroom challenges: Western-educated faculty experiences in a Gulf classroom context. Proceedings of The International Conference on Intercultural Communication Competence: Implications for Business, Education and Politics, Singapore, October 6-7 2006.

Kolb, D. A. (1984). Experimental Learning: Experience as the Source of Learning and Development. Englewood Cliffs, NJ: Prentice Hall.

Long, R. (1999). 20/20 Hindsight: Teacher change and advice. The Internet TESL Journal, Vol. 5 (11), 1-11. Accessed 25 February 252003 at <http://iteslj.org/Articles/Long-TeacherChange.html>

Loughran, J.J. (2002). Effective reflective practice: in search of meaning in learning about teaching. Journal of Teacher Education, Vol. 53 (1), 33-43. 
Paulus Nicol, M. (2000). Changing habits of a lifetime. ENC Focus, 7(1). Accessed 1 May 2002 at http://www.enc.org/professional/learn/change/context/change.

Richardson, V. (1990). The evolution of reflective teaching and teacher education. In R.T. Clift, R.W. Houston, M.C. Pugach (Eds.), Encouraging Reflective Practice in Education: An Analysis of Issues and Programs (pp. 3-19). New York: Teachers College Press.

Risko, V.J., Roskos, K., Vukelich, C. (2002). Prospective teachers' reflection: Strategies, qualities, and perceptions in learning to teach reading. Reading Research and Instruction, 41 (2), 149-175.

Russell, A., Wadie, S., Khelifa, M., \& Jendli, A. (2006). Arab States: United Arab Emirates. In J. J. Arnett (Ed.). Routledge International Encyclopedia of Adolescence.

Schön, D. A. (1983). The Reflective Practitioner. How Professionals Think in Action. New York: Basic Books.

Schön, D. A. (1987). Educating the Reflective Practitioner. San Francisco: Jossey-Bass.

Shatz, M. A. 2000. Teaching psychology in Hong Kong: Pedagogical challenges, instructional solutions, and lessons learned. Teaching of Psychology, Vol. 27 (2), 140.

Smyth, J. (1998, Winter). Teachers theorizing their practice as a form of empowerment. The Educational Administrator, 30, 27-37.

Sommer, R., \& Sommer, B. A. (1991). Teaching psychology in Estonia, USSR. Teaching of Psychology, Vol. $18(2), 107$.

Sonleitner, N., \& Khelifa, M. (2005). Western-Educated faculty challenges in a Gulf classroom. Learning and Teaching in Higher Education: Gulf Perspectives, Vol. (2), 1-21. Accessed 1 February 2009 at <http://www.zu.ac.ae/Ithe/vol2no1/lthe02_02.pdf>.

SPSS Text Analysis for Surveys 1.0 User's Guide (2004). Chicago, IL: SPSS, Inc.

Thielfoldt, D. \& Scheef, D. (2005). Generation X and the Millenials: What you need to know about mentoring the new generations. Law Practice Today, November 2005. Accessed 1 April 2008 at <http://www.abanet.org/lpm/lpt/articles/mgt08044.html>.

Tom, A. R. (1985). Inquiry into inquiry-oriented teacher education. Journal of Teacher Education, 36 (5), 35-44.

Van Manen, M. (1977). Linking ways of knowing with ways of being practical. Curriculum Inquiry, 6, 205228.

Walker, D., \& Boud, D. (1992). Facilitating critical reflection: opportunities and issues for group learning. A Quarterly Experience (Australian Journal of Experiential Learning), 29, 10-20.

\section{Author}

Dr. Maher Khelifa is Associate Professor, Department of Humanity and Social Sciences, College of Arts \& Sciences, Zayed University, Dubai. Maher has over twenty years of teaching experience including ten years at Zayed University. His current research interests are in the areas of teaching and learning in cross-cultural contexts and undergraduate research. 


\section{Appendix A: Instrument of Data Collection}

This questionnaire explores teaching changes in the classroom at Zayed University that teachers make - regardless of area of specialty - in order to achieve instructional effectiveness. There are no wrong answers. You are assured that no one other than the investigators will have access to your response nor will you be identified when the results are written. Please answer the questions to reflect your own experience and opinion.

\section{Please provide the following demographic information about yourself.}

- Gender: Male___ Female

- Citizenship:

- English is my:

First language___ Second language___ Third language___ Other

- Highest level of education:

- In which country did you receive your highest level of education?

- Present Academic Rank:

- Instructor

- Assistant professor

- Associate professor

- Professor

- Years of Western university teaching experience prior to ZU:

- Undergraduate level

- Graduate level

- How long have you been teaching at ZU:

- Before coming to $\mathrm{ZU}$, did you have previous teaching experience in a university where English is not the first language?

Yes No

- If yes, how many years?

- Please indicate your responses to the following questions.

1. Have you encountered any student-related classroom challenges when teaching at Zayed University? Yes___ No

If your answer is "Yes" please continue. If your answer is "No" please stop here.

2. Please use the space below to list, by order of importance, the top five student-related classroom challenges you have encountered.

\section{1.}

2.2 .

2.3.

2.4 .

Khelifa, M. (2009). Reflective Practice in a Cross-Cultural University Setting: A Theoretical Model. Learning and Teaching in Higher Education: Gulf Perspectives 6(1). http://www.zu.ac.ae/Ithe/lthe06_01_01_khelifa.htm 


\section{5.}

3. Have you developed any strategies to address the challenges you have listed above? Yes No

\section{If your answer is "Yes" please continue. If your answer is "No" please stop here.}

4. Please describe the process you go through as you developed your teaching strategies to address any challenges you have experienced.

5. When you develop solutions/strategies to challenges, do they involve any changes in your teaching?

Yes

No

\section{If your answer is "Yes" please continue. If your answer is "No" please stop here.}

6. Using the list below, tick the teaching areas that you have changed.

Teaching method
Teaching pace
Course content
In-class explanation
Assessment frequency
Grading practices
Other (please specify)

7. In reference to the teaching areas selected in question 6 , in general how often do you find yourself having to make changes to your teaching?

Once or twice a year

Once a semester (or once a 10-week course)

Once a month

Once a week 
After almost every class

Other (please specify)

8. Using the same list as question 6 , check the top three areas in which you think you have changed substantially.

_ Teaching method Teaching pace Course content In-class explanation Assessment frequency Grading practices Other (please specify)
Motivational strategies Assignment frequency Course preparation Language use Assessment rigor Expectations of students performance

9. Please briefly explain how you have changed in respect to the three areas you have selected in question $\mathbf{8}$.

10. In general, what motivates you to make changes to your teaching? Please check the top 3 reasons.

To have control over the classroom environment.

To have students assume responsibility for their own learning.

To reach more students (make more students understand classroom content).

To motivate students and interest them in the learning process.

To increase students' participation in classroom activities.

To improve the quality of students' work.

Other (please specify)

11. What type of support do you draw on in the process of finding solutions/strategies to classroom challenges? Please check what applies.

I do not seek support in my process.

I discuss with students their classroom challenges 
I ask students to suggest solutions/strategies

I discuss classroom challenges with other ZU faculty members

I ask other ZU faculty to suggest solutions/strategies

I discuss classroom challenges with faculty from other institutions

I ask faculty from other institutions to suggest solutions/strategies

I discuss with dean or assistant dean classroom challenges

I ask dean or assistant dean to suggest solutions/strategies

I refer to relevant scholarly literature for support materials

12. Do you draw on students' feedback in the process of teacher change?

Feedback is defined as any type of subtle messages (motivation, facial expression, body language, etc.) or explicit messages (verbal cues, written cues, behavioral cues, students' evaluation, etc.) students send in a classroom context.

Yes

No

If your answer is "Yes" please continue. If your answer is "No" please stop here.

13.1. Do you find students' feedback instrumental to the process of teacher change?

Not at all instrumental

Not very instrumental

Somewhat instrumental

Very instrumental

13.2. List the type of student feedback you have used to make changes in your teaching?

13.3. What type of student feedback do you find the most useful to the process of teacher change?

Thank you very much for your participation. 